\title{
O Estudo da Concentração de Poluentes na Atmosfera utilizando Parâmetros Fuzzy e Fronteira Mista
}

\author{
Jennifer Cristina Borges* Rosana Motta Jafelice \\ Faculdade de Matemática, UFU, \\ 38400-100, Uberlandia, MG \\ E-mail: jennifer@famat.ufu.br, rmotta@ufu.br,
}

\begin{abstract}
RESUMO
O objetivo desse trabalho consiste na modelagem matemática de uma fonte de poluição que consideramos sendo uma chaminé de indústria que contamina a atmosfera como uma nuvem de poluição que se espalha por uma cidade hipotética. Inicialmente, este estudo foi realizado apenas com a dispersão sendo um parâmetro fuzzy [3]. Consideramos o problema através de uma equação diferencial parcial evolutiva advectiva-difusiva em um domínio retangular, com condição de fronteira mista (Dirichlet e Neumann) e os parâmetros dispersão e velocidades no eixo $x$ e $y$ são calculados através de um Sistema Baseado em Regras Fuzzy (SBRF) [2]. Na região consideramos uma das fronteiras com condição de Neumann dada por $u_{x}(x, y)=-k u$ onde $k>0$, como mostra a Figura 1.
\end{abstract}

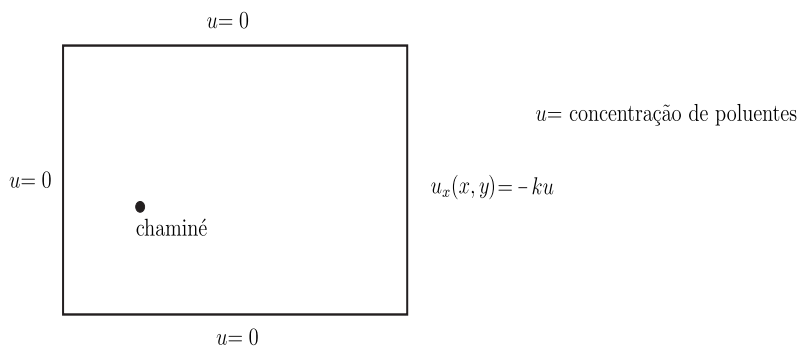

Figura 1: Região retangular com as fronteiras mistas e a localização da chaminé da indústria.

A equação deste fenômeno é representada por:

$$
\frac{\partial u}{\partial t}-\alpha(T, P, U, u)\left(\frac{\partial^{2} u}{\partial x^{2}}+\frac{\partial^{2} u}{\partial y^{2}}\right)+v_{1}(A) \frac{\partial u}{\partial x}+v_{2}(A) \frac{\partial u}{\partial y}+\sigma u=f
$$

onde $u(x, y, t)$ é a concentração de poluentes no instante $t, \alpha$ representa a dispersão na área, $v_{1}$, e $v_{2}$ são as velocidades de transporte em $x$ e $y$, respectivamente; $\sigma$ representa o decaimento e o $f$ a fonte de poluentes (neste trabalho, a chaminé). Consideramos que a dispersão e as velocidades são calculadas em função de algumas características da posição da malha através de um SBRF. Vamos utilizar a temperatura $(T)$, a umidade relativa $(U)$, a pressão atmosférica $(P)$ e a concentração de poluição $(u)$ de cada ponto da malha como fatores que influenciam a dispersão $\alpha$. As velocidades são fatores importantes no estudo da concentração do poluentes, principalmente quando levamos em consideração a força de atrito que é provocada pelo relevo, pela presença de edifícios, pela vegetação e outros fatores. Assim, consideramos que as velocidades dependem da força de atrito $(A)$. Esta informação foi baseada no especialista na área de climatologia [4]. Este estudo com a fronteira de Dirichlet foi realizado em [1]. Os fatores que influenciam a dispersão e as velocidades são representados pelas funções:
- $T(x, y)=39 e^{\left(\frac{\left(-(x-1)^{2}-(y-0.5)^{2}\right)}{5}\right)}$;
- $P(x, y)=e^{\left(\frac{\left(-(x-1)^{2}-(y-0.5)^{2}\right)}{4}\right)}$;
- $U(x, y)=0.8 e^{\left(\frac{\left(-(x-1)^{2}-(y-0.5)^{2}\right)}{8}\right)}$;
- $A(x, y)=e^{\left(\frac{\left(-(x-1)^{2}-(y-0.5)^{2}\right)}{2}\right)}$.

*Bolsista de Iniciação Científica SESu/MEC até fevereiro de 2014 e Bolsista de Mestrado CAPES início março de 2014 
A dispersão $\alpha$ é calculada utilizando um SBRF onde as variáveis de entrada são funções de per-

tinência triangulares e os termos linguísticos são: baixa, média e alta; e as funções de pertinência da variável de saída são triangulares e termos linguístico são: muito baixa, baixa, médio 1, médio 2, alta e muito alta. Um exemplo de regra fuzzy é: se a pressão é baixa, a temperatura é alta, a umidade é baixa e a concentração de poluentes é média então a dispersão de poluentes é muito alta. As velocidades $v_{1} \mathrm{e}$ $v_{2}$ são calculadas utilizando um SBRF onde as funções de pertinência das variáveis de entrada e de saída são trapezoidais e os termos linguísticos são: baixa, média e alta. Um exemplo de regra fuzzy é: se a força de atrito é alta então as velocidades $v_{1}$ e $v_{2}$ são baixas. Na saída dos SBRF, obtemos diferentes valores de $\alpha, v_{1}$ e $v_{2}$ para cada ponto da malha discretizada da região. Como a equação (1) não é linear, é necessário determinar a dispersão da poluição no presente instante afim de encontrar a solução em cada tempo posterior. Assim, utilizamos o cálculo da extrapolação da concentração da poluição através de $u_{e x t}=\frac{3}{4} u_{i+1}-\frac{1}{2} u_{i}, i=1,2, \ldots$, obtendo a concentração neste instante e determinamos a dispersão pelo SBRF em cada instante. Assim, a aproximação da solução numérica da equação (1) é obtida utilizando o método das diferenças finitas, o método de Crank-Nicolson e os parâmetros fuzzy $\alpha, v_{1}$ e $v_{2}$.

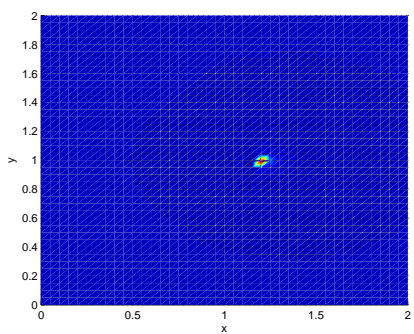

Figura 2: Condição inicial da concent. do poluente.

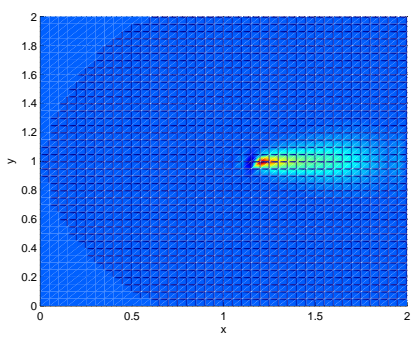

Figura 3: Concent. do poluente após 20 iterações.

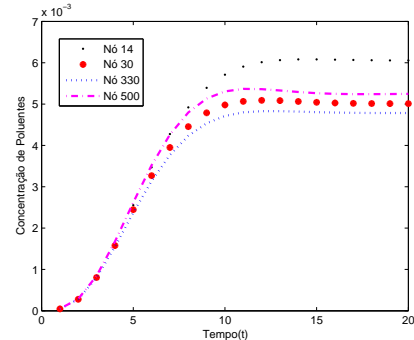

Figura 4: Concent. de poluentes nos nós 14, 130, 330 e 500.

A Figura 2 apresenta o gráfico da condição inicial do poluente. Podemos observar que na Figura 3 houve perda de poluente na fronteira onde temos a condição de Neumann. As simulações foram feitas em quatro nós, com a finalidade de identificar a melhor localização para construir outras indústrias na cidade. Esta identificação é realizada observando-se onde a concentração de poluentes assume o menor valor, Figura 4. Pelas quantidades de poluentes em cada nó desta figura, nota-se que a região mais adequada para a construção de outras indústrias é a próxima do nó 330. Neste trabalho determinamos a melhor localização para um pólo industrial dentre os quatro nós estudados. Esta conclusão só foi possível porque a dispersão e as velocidades foram consideradas como parâmetros fuzzy.

Palavras-chave: Conjuntos Fuzzy, Fronteira Mista, Equação Diferencial Parcial.

\section{Referências}

[1] J. C. Borges, R. S. M. Jafelice, Abordagem Fuzzy para a Concentração de Poluição do Ar, Anais da XII Semana da Matemática-SEMAT, Uberlândia - MG, 2013.

[2] R. M. Jafelice, L. C. Barros e R. C. Bassanezi, "Teoria dos Conjuntos Fuzzy com Aplicações", Notas em Matemática Aplicada 17, SBMAC, 2ª edição, 2012.

[3] C. C. Oliveira, H. C. Mello, R. S. M. Jafelice e J. F. Meyer, A Model of Dispersion of Pollutants in the Air using Fuzzy Parameters, International Symposium on Mathematical and Computational Biology, Rio de Janeiro - RJ., 2010.

[4] L. A. Oliveira, Estudo de Caracterização Climática e de Direção Predominante dos Ventos da Cidade de Uberlândia/MG, Relatório do Laboratório de Climatologia e Recursos Hídricos, Universidade Federal de Uberlândia, 2010. 